\title{
On the Correspondence Between Visual and Gustatory Perception
}

\author{
Nicola Perullo
}

\section{Introduction}

We are currently facing a curious paradox: taste, usually thought of as a 'minor sense' in the sensory hierarchy, is celebrated and 'culturalised' first and foremost through vision, the supreme sense par excellence. ${ }^{1}$ It is visible to everyone: gastronomy, cooking, food and wine in general

1 To cut a long story short, the general objections against the philosophical importance of gustatory taste and its consequent disregard has fallen into three areas: epistemology, aesthetics and ethics. An epistemological weakness has often been proposed, together with its aesthetic consequence: taste belongs to the minor senses because it does not allow for a powerful and objective knowledge of the outer world as the major senses (sight and hear) do. This weakness matches then with the ethical dangers of gluttony and excess. See for instance Elizabeth Telfer, Food for Thought: Philosophy and Food (New York: Routledge, 1996); Carolyne Korsmeyer, Making Sense of Taste, Food and Philosophy (Ithaca, NY: Cornell University Press, 1999); Nicola Perullo, Taste as Experience. The Philosophy and Aesthetics of Food (New York: Columbia University Press, 2016). 
have acquired their own place as objects of education, reflection and appreciation. This paradox has actually just become apparent: the process to the visualisation of taste was born and developed in the context of the scientific and philosophical revolutions of modernity; science as analytic and experimental method, and philosophy mostly conceived as epistemology produced a model of knowledge based on the distinction between subject and object. In this context, taste is supposed to be important only as 'something' we should analyse and, then, objectivise. $^{2}$ This process coincides with the birth of aesthetics in the eighteenth century, the 'Century of Taste.' ${ }^{3}$ A theory of subjectivity and judgement went along with a new sensibility for artworks and, more in general, artefacts, including gustatory ones. During the same period that gastronomy became a socially established practice, restaurants as well as public museums were established.

With respect to the relation between visual and gustatory perception, however, something new occurred in the last century, with the invention of photography and cinema, and with the digital revolution. In the most diverse areas of pop culture, there is a growing proliferation of visual images: gastronomy and taste play an eminent role in this process, considering the vast numbers of websites, blogs, television programmes, movies and photos dedicated to food: Master Chef and similar reality shows, but

2 See Steven Shapin, 'The Sciences of Subjectivity', Social Studies of Science 43 (2012): 170-184.

${ }^{3}$ See George Dickie, The Century of Taste: The Philosophical Odyssey of Taste in the Eighteenth Century (Oxford and New York: Oxford University Press, 1996). 
also phenomena like food porn and foodstagramming. A visual image, however, is not unique and can take different forms: a string of written signs is as visual an image AS a photograph, a painting, a line on the sand. It is therefore necessary to clarify whether this variety also means differences in content and outcomes, or whether the relationship between the image and the gustatory perception works similarly across the board. The image expresses, evokes, indicates and shows, whatever this means. To show is to demonstrate, prove, and make something evident to the senses and the intellect through sight. To show is to show something, an object, a merchandise, a body, a dish, a bottle of wine, through a sign. What does it mean then to show what should be principally valued and celebrated through the appreciation and enjoyment of gustatory taste?

However much we argue about it, we do not sit at the table, whether at home, at a restaurant or a wine bar, in order to contemplate the dishes or to read labels on wine bottles; rather, we sit down in order physically to eat, drink and consume, although at times - as if to underline the difference - we talk about tasting and culinary experimentation. This is largely because the visual admiration of a dish or the reading of a wine label neither sate us nor satisfy us in their own accord. What is, then, at stake when we visually appreciate culinary artefacts, to the point that sometimes we develop an unconditional admiration for a cook based on purely visual judgement, or we predetermine a wine's taste simply after having read its label? This is the general question I would like to explore in this chapter, which is divided in two parts. In the first part, I discuss the relation 
between sight and taste through the case of the wine label, as presumed carrier of information that should supposedly prefigure the taste of the wine. In the second part, I deal more generally with the relation between images and food through an understanding of cooking as art, something that is very important today with regards to the role assumed by chefs as creators, authors or artists. The answer I suggest is that the relation between visual and gustatory perception is a continuous relation of correspondence. I need to make one important clarification: as I show below, by 'correspondence' I do not mean here any 'adaequatio', any accord, between vision and taste, in the manner of 'adaequatio rei et intellectus'. Drawing from Tim Ingold's work, instead, I would define it as the ongoing and continuous relationship and exchange between the two, like in postal correspondence: questioning and answering that can be the base of agreement, as well as disagreement and excess. ${ }^{4}$ This goes into two different but related directions. On the one hand, the experience of taste, the actual tasting, always exceeds the image. On the other, the image guides, defines, determines and prescribes taste. This double implication restores an important role to vision and calls for an ethical commitment to the production of images. The perspective I am proposing here is then also a critique of the standard conception that sees taste as a 'minor sense' with respect to sight and hearing: as I try to indicate, single senses are just an abstraction. In fact, taste has always been enhanced by vision and this is particularly true today; yet,

${ }^{4}$ See Tim Ingold, The Life of Lines (London and New York: Routledge, 2015). 
at the same time, in the case of food, visual perception is also shaped by gustatory perception, in a dynamic process of mutual correspondence.

\section{2. (Don't) Read the Label}

As I write these lines I'm drinking a wine called Iconoclaste. Curious! Before me, and little by little inside me, the very paradox I would like to write about unfolds. Here, before me: in front of my eyes, near my mouth. I have a wine label that denies itself, because it calls for the negation of its visual appearance. The paradox I want to point out here it is not just about Appellation, Denomination or Geographical Indication (to which I return below). It is about the more general question: what does a visual image - a label - show, express or indicate? In this case, it seems that Iconoclaste explicitly suggests its own suppression. But does it work differently to other, more polite and conventional labels?

As it is well known, a label is not just a mark. It can be a sign but also a symbol or even an icon. It indicates a relationship with a source, a presumed point of origin - a physical site, a Denomination, a property - from which a process flows, a chain leading to an end: the end of the process, and the purpose of the process. Some labels describe or evoke the process itself. In the case of food or wine, its consumption. The label is made to be consumed, indeed destroyed. It is like a road sign pointing towards a city: it cannot properly express that city, it can only evoke it, allude to it. Therefore, a label does not really signify anything, as the promise of an experience, vis-à-vis its 
content. It indicates, alludes and evokes but does not signify, at least as far as we believe that to signify would mean to produce a tight relation between the word or sign and the 'thing': how much can a label reading 'Barolo' of a given vintage and producer, guarantee the experience I will have of this wine? Very little, and this little does not depend on the meaning of the label but, possibly, on the memory of previous experiences. Thus, the iconoclasm appears less paradoxical than we think: a wine label is a sign pointing to what, by definition, will not leave traces about - apart from the memory of those who drank it, or the writing of those who write about it. Historically, writing about food and wine taste has been the trace of what is no longer present. Taste and writing, in this sense, shared a common destiny that wedded them to sight and orality in a subordinated and marginal life, as opposed to a supposedly 'full' presence. ${ }^{5}$ The question is anything but abstract or speculative. Label issues, although having to do with law and regulation, directly open up the issue of justice: is it possible to do justice to a wine through the mere reading of a label? No, it would seem, yet it is not that simple. Let us look at this point in detail.

On the one hand, even with the best intentions the label cannot say everything about the wine. Here, I am not referring to the debate about whether or not to inform the buyer about all the ingredients that a wine contains. The problem rather concerns the questions of the authenticity and quality of memory, expected taste and aesthetic

5 The classic reference here is Jacques Derrida, Writing and Difference (Chicago, IL: University of Chicago Press, 1978). 
experience. Let us take two (Barolo), same vintage and same Cru. The first comes from a family, resident in the Langa for many generations. The second is made by a young Swiss couple that has arrived a few years ago, and originating in different professional backgrounds. Let us hypothesise - in fact, this is often the case - that the wine has been elaborated in very different ways. Were we to ask which is the more authentic of the two (Barolo) - which one expresses more profoundly its territory - what could bring us closer to provide an answer? As we know, the label cannot tell us anything about such differences (and often, in fact, it does not say anything at all), and thus would be of no help to establishing which is the more authentic. Only the experience of drinking would provide a basis for an answer. Authenticity is not defined abstractly, because it is a continuous process of authentication. One might even conclude, and perhaps this is the most probable solution, that the two (Barolo), albeit so different, are both authentic, thus tuning our measure of authenticity to broader criteria and recognising among them, thanks to the gustatory experience, some traits and 'family resemblances'. In this respect, therefore, the label will never be able to say everything. The map of the territory is not the territory. Words and images are not the things.

On the other hand, however, something very different may occur, able to reinstate an absolute normative power to the label - something that would go beyond the indexing logic pursued so far: we may simply entrust it to resolve the tasting dispute. To us, the two (Barolo) appear to have a completely different taste, yet they are both (Barolo), since the law says so. On a closer look, this 
power of the label is a power of sight: the label should be read. In this case, writing moves from witnessing the experience to prescribing it. The power of writing - and consequently of the visual image, of a label - is performative and prescriptive: that wine is a Barolo insofar as we name it as such, and the taste is moulded according to the performative power of naming. ${ }^{6}$ Of course, the prescriptive power of the label is not born out of a random event: it is the result of a long normative process that led to the creation of various types of geographical denominations.

With respect to wine, three relevant aspects qualify such denominations: (i) they identify a spatial range, a given geographically delimited area, (ii) they have no temporal limits, and (iii) they identify some properties considered essential to the protected object, in this case the wine. With respect to our example: the 'Barolo' DOCG classification is determined according to some portions of land within a given area corresponding to some of the Langhe municipalities; the 'Barolo' DOCG has no temporal limits; the 'Barolo' DOCG is subjected to a set of rules [disciplinare] regulating certain aspects that are deemed necessary - according to both viticultural and oenological ambits - for a drink obtained from the alcoholic fermentation of certain grapes to be bottled with such label. The first two aspects refer to what is termed 'terroir.' The third aspect, instead, refers to technological and scientific elements. ${ }^{7}$

6 See John L. Austin, How to Do Things with Words (Oxford: Oxford University Press, 1962).

7 See Andrea Borghini, 'On Being the Same Wine', Rivista di Estetica 51 (2012): 175-92. 
These three aspects, however, simply corroborate the thesis on the paradoxical nature of the label and the norm that produces it, an ultimately circular paradoxicality. Without going into details, it is enough to recall the following: a terroir, an area, a cru are a constellation of climate and microclimate, the life of the soil and of all those elements that create a given ecosystem, obviously including the anthropic one, together with traditions as well as individual and communitarian styles. All this however is not static, it is produced and modified constantly (for instance, we may think about the impact of global warming on the ripening of a fruit, or about the unpredictability of winds, or even the different hands and feet that will walk the vineyard, or about the trenching, the erosions, the roads built near the vines). Where are to be situated the boundaries containing the domain(s) of identity? And of course, who makes this decisional process work, how and when? We all know it is a social body, a varied community composed by makers, experts, markets, aficionados, etc. But is this all we can say about this? The terroir is a living organism that changes in spatial and geographical, temporal and historical, as well as social and cultural terms. Same for the third aspect, the one concerning technology: there exist so many different styles and projects to make a wine, and just as many variables - dependent on conscious choices as well as uncontrollable factors - that it is impossible to include them all in a definitive and final piece of regulation. In fact, in the last 30 years we have seen regulations [disciplinari] adjusting to the modifications that each of the three aspects have undergone. To put it differently, it is as if the 
law - and especially the label, as the law's most immediate and commercial expression - would often ratify practices and criteria coming from external drives: the market, the consumers, the enthusiasts and the experts.

Hence the circularity I was alluding to: both the identification by a legislator of a static physical space, and the rigid protocols that regulate dynamic processes are abstractions. Perhaps necessary abstractions, but surely insufficient, since they do not anticipate the modifications that continuously occur, but rather merely ratify them, with the result that they always and unavoidably arrive aprés-coup. At the same time, once ratified, a regulated modification also becomes prescriptive of future perceptive experiences. This happens because taste is partially 'blind': insofar as being a singular and specific experience, it cannot encompass the entire area to which such a norm refers. The relation among words, images and taste therefore, is a relation of mutual correspondence, as already stated, in the postal meaning of this term: a word/image calls, the taste (cor)responds. The taste calls, a word/an image (cor)responds. ${ }^{8}$ Such correspondence is not necessarily an accord: it may also produce discordances that will be put back on the correspondence's negotiating table in order to produce novel spaces of communication and accord.

\section{Vision of Taste, Taste of Vision}

One of the main reasons for which the so-called 'haute cuisine' and the great cooks of today enjoy unparalleled

\footnotetext{
8 See Ingold, The Life of Lines.
} 
social and cultural success in relation to the past, is that this is the Age of World Picture, becoming in turn the Age of Food Picture, to paraphrase Heidegger. What is again at stake in this process is the apparently paradoxical nature of the sensorial hierarchy: instead of restricting taste, sight enriches and stimulates it through its ability to make the edible appetising to sight itself (a desirability that is not necessarily physical). In fact, in one sense it has always been so: remind just the medieval banquets, with their rich scenography in which plays, music, colours created a multisensorial taste experience, a real food show. But in another sense, the phenomenon is also very new: mediatisation, especially after the digital revolution, played and still plays a paramount role. ${ }^{9}$ On the one hand, it is very easy to be critical of it: the aestheticisation of everyday life reveals in fact an anaesthetisation, a loss of 'real' experiences replaced by a visual apparatus, variously called 'virtual' or 'augmented' reality; as some scholars stated, this has to do with the age of aesthetic capitalism. ${ }^{10}$ Food images are good examples, as we see below. On the other hand, things are not that simple and, again, I shall propose a different approach based on the relational idea of correspondence between vision and taste. If we cannot escape from an appreciation of the so-called 'gastronomic' senses - taste, smell, touch - in a global, multisensorial way, audition and (especially) vision has

9 See Nicola Perullo, 'Can Cuisine be Art? A Philosopical (and Heterodox) Proposal', in The Taste of Art: Cooking, Food and Counterculture in Contemporary Practices, eds, Silvia Bottinelli and Margherita d'Ayala Valva (Fayetteville, AR: University of Arkansas Press, 2017), 23-44.

${ }^{10}$ See Gilles Lipovetsky and Jean Serroy, Lesthétisation du monde: Vivre à lâge du capitalism artiste (Paris: Gallimard, 2013). 
to be included in this. We should look then for images deeply involved in the processes of gustatory perceptions as complex experiences, that is, images that correspond to them and vice versa. To correspond is to respond, to be able to respond to a call; and this is the original meaning of the word responsibility, being able to respond. This is a challenge that calls for an ethics of the gaze, an ethics of responsible food pictures beyond easy explanations and journalistic trivialisations.

Let us begin from a simple fact: as the saying goes, one also eats with the eyes, and this is because there is a continuous relation between visual and gustatory perception. According to James Gibson, taste is more than the totality of flavours and gusto-olfactory reactions and relations. Gibson has proposed an 'ecological approach' to perception that concerns also gustation. Taste is a multimodal perception, a 'perception sense' and not a 'sensation sense'. Every time, different saliences and affordances are put into play. ${ }^{11}$ In that sense, and because of the history of humankind, sight occupies almost always a privileged and dominant position. We shall radicalise now the multisensorial quality of taste. If taste, as any other sense, is not an isolated dispositif but functions together with the other senses, then the senses as isolated dispositives do not exist on the perceptive plane: this simply is an abstraction. It is therefore incorrect to speak about the influence of sight over taste or, conversely, of taste over sight, as was analysed earlier with respect to the question

11 See James J. Gibson, The Senses as Perceptual Systems (Boston, MA: Houghton Mifflin, 1966). 
of labels. The supposed 'hierarchy of the senses' cannot be overcome by claiming recognition of the specific domain of each sense. One should rather speak about the differential planes and specific articulations of a unique sentient body. ${ }^{12}$ We taste food by eating it, but we also think, look, feel and touch while eating; when feeling the waves of the sea, we look, we touch, we hear, etc. Let us, therefore, take taste as a specific articulation - a point of emergence of the sentient body - and let us focus on some of its relations with sight - another peculiar emergence on the perceptive place - without, however, forgetting its relation of continuous and dynamic correspondence with the whole sentient plane.

It would, therefore, make no sense to underestimate sight's relevance for taste, and thus for the cooked food that is eaten. This is evident in the Italian expression 'acquolina in bocca' (literally, 'mouth-watering', or 'salivating at the thought'), and it often suffices to think the extent to which the colour of a food can affect its taste, whether positively or negatively. Let us take two examples. The first is the case of vegetarian cuisine. Historically driven by ontological, ethical or religious issues, the great tradition of vegetarianism has often generated refined visual and formal constructions, occasionally by imitating carnivore-dish appearances. Far from being a sign of disvalue

${ }_{12}$ The classic reference is, of course, Maurice Merleau-Ponty, Phenomenology of Perception (New York: Routledge, 2012) and also, and especially, Maurice Merleau-Ponty, The Visible and the Invisible (Evanston, IL: Northwestern University Press, 1969) and Michel Serres, Les cinq sens (Paris: Grasset, 1985). 
and disesteem, this process of imitation shows how visual memory can be powerful, stimulating appetites and inducing taste values. As it has been shown, in societies where the carneo-paradigm is largely prevalent, the assumption that meat is more appetising is strong, so dishes such as soy steaks, fruit lobsters and many more are produced. The second example is the case of haute cuisine, that is the cuisine of the gourmet, authorial, sophisticated, avantgarde kind. The contribution of visual perception to taste has been consciously emphasised and underlined (according to what, approximately and imprecisely yet commonly accepted, is called 'aesthetics', in the sense of exhibition and appearance to sight). As we know from cuisine historians, the sumptuous medieval banquets gave as much relevance, if not higher, to the staging elements - musical, theatrical, chromatic features - as to the gustatory ones. More precisely: a food or meal's taste was to be the synthesis of all these elements. Although, subsequently, the history of modern art and aesthetics accustomed us to neatly distinguishing and separating, at times even opposing, the various sensorial domains, this has not been the case for a long time. ${ }^{13}$ It is quite traditional to appreciate gastronomy and cooking as design - its form, colour, construction, project. It is not by chance that, in Western culture, the most immediate assimilation of cooking with art was done through the analogy to architecture and sculpture, valorised as visual perception. ${ }^{14}$

13 See Sylvie Davidson and Fabrizio Lollini, eds, Le arti e il cibo: Modalità ed esempi di un rapporto (Bologna: Bononia University Press, 2014).

14 See Marie-Antoine Carême, Le pâtissier pittoresque (Paris: Hachette, 2013). 
Today, visualised food is so common as to have become trivial. Films, videos, and above all photography, dominate not only the narrow niche of foodies and gastronomes but also global pop culture. In fact, as said earlier, the current explosion of cooking as a cultural and mass-media phenomenon, testified by the veritable gastro-mania for food reality shows such as Master Chef, is a consequence of the digital revolution, which had a profound influence both on the image, and critique, of food. ${ }^{15}$ Everyone takes pictures of food, dishes, meals: a potentially infinite image archive of foodstagramming and food porn. In this context, the experience of eating has become explicitly visual as much as gustatory, in the most transversal way: from the most sinister food porn, to refined and polished haute cuisine magazines and books, increasingly conceived as coffee table books, to be enjoyed as veritable art catalogues. Here, the image of dishes has no instructive value, it is not useful for a dish preparation recipe, but only valuable in itself as work of art. Also in this case then, the relation between vision and taste assumes an ambivalent character. On one hand, it promotes the culturally marginal practice of cooking, elevating it to the level of art, and this is obviously the case of 'high' cuisine that said relation presents and celebrates. Today, cooking is culture, as anyone with the minimum of curiosity about the world can appreciate. One can learn everything about a chef's 'philosophy' by looking at their dishes on books, social media, videos, without ever having entered their restaurant, if they have one. This phenomenon may

${ }^{15}$ See Gianfranco Marrone, Gastromania (Milano: Bompiani, 2014). 
enrich a culture as well as create a consciousness. On the other hand, however, it risks obfuscating the significance of the concrete, real and material experience of both cooking and consuming the food, in favour of its media spectacularisation. ${ }^{16}$ The price to pay for the planetary diffusion and consumption of food images is potentially high: the progressive virtualisation of such culture, a rarefaction as result of which one looks more and more while cooking, but experiences less and less, or with less awareness. Is it possible to eschew this outcome, avoid the risk of an image overdose - which can be observed also in the praxis of many cooks elaborating their dishes as if they were visual designers - in order to propose a productive relation with the vision of taste? Is a positive relation with food possible in this context? It is, although it is not easy: it is a matter of disentangling the realisation of a dish from its merely virtuoso exhibition, that often degenerates into the studied exhibitionism of the creator of the dish, and the compensatory voyeurism of the observer of the image. This could be done in favour of a dimension able to grasp the profound sense of this relation, and to link it to the dimensions of memory, passion, care, and engagement.

For such a productive vision of taste, a 'levelling strategy' is required. In terms of aesthetics, this entails refraining from elevating cooking to the level of art as if this would sanction its value. This is the most common operation, not only among artists and art theoreticians, but also among cooks. Instead, it is a matter of levelling art to the level of

${ }_{16}$ See Lipovetsky and Serroy, Esthétisation du monde. 
cooking. ${ }^{17}$ What does that mean? Thinking art as cooking means thinking it as a material practice of sensible, perishable and contingent processes. The ability to understand art is ancient and modern at the same time. Ancient, since tied to a paradigm that today has been relatively forgotten, according to which 'art' indicates a technical skill, a craft, a techne, a perfect and concrete know-how, related to the execution of both material (a jewel, a pair of shoes, a culinary dish) and intellectual objects. Modern, since it concerns a modality of art generation as a specific aesthetic and cultural experience, and as a consumption good, that has been established only in the last few centuries. In the age of the technical reproduction of any artefact, and of pervasive aestheticism, art has become other vis-à-vis its traditional conceptualisation in terms of superiority and exceptionality. That is, whether today everything, including art in its entirety, is pop - as many scholars maintain, I believe, with good reason - then it is not clear why cooking, in order to be art, should take off the apron, clear the table, and make space for a desk wherein to project, ideate and design something superior and exceptional that will be then simply prepared and eaten, as if preparation and ingestion would be a degradation to that higher and elevated dimension.

Yet, this is not the case, and there are convincing reasons for this. Let us take, for instance, the notion of aura. Pondering on the new languages of photography and cinema, Walter Benjamin in The Work of Art in the Age of Mechanical Reproduction points out the loss

${ }^{17}$ See Perullo, 'Can Cuisine be Art?', 23-44. 
of aura that characterises the contemporary production of artworks. Because of its infinite reproducibility through technology, a work of art loses its uniqueness and authenticity that derives from its inability to being repeated in space and time. However, Benjamin anticipated that a novel manifestation of the aura would occur through these very technologies. Today, the aura would be the 'technical equivalent' of things. In this sense, it is the food's global digital dissemination that would bring about its attraction and magnetism. However, we can also take a different path for understanding aura in the specific situation of gastronomic experience. In fact, an argument can be made that the cooking aura would consist of the concrete experience of sitting at a table and tasting the dishes: an always unique and irreproducible experience that images shared instantaneously can only partially evoke. This consideration should prompt us to valorise the whole process of creation of a dish: from the ideation (project or intuition) to the preparation (similarly irreproducible insofar as dependent to gestures, hands, actions) up to the actualisation, that is, the moment when the dish enters the stage, appearing on the table as part of a meal that may be organised in many different ways. ${ }^{18}$

The levelling strategy, therefore, requires, at the same time, a strategy of broadening the horizon of art: art is no (longer) only tied to seeing and hearing, as many still think especially in the gastronomic field, trapped within

18 See Gianfranco Marrone, 'Goodman in cucina: le attivazioni di Babette', in Cibo, filosofia e arte, ed., Nicola Perullo (Pisa: ETS, 2014), 69-81. 
the modern paradigm of 'fine arts'. Art is also tied to touch, taste and smell. Such a strategy would radically flatten the sensorial hierarchy that structures western modern art, in which touch, taste and smell occupy the lowest spots. Hegel observes in Aesthetics that artistic enjoyment only refers to the theoretical senses of sight and hearing, and not to touch, taste and smell. In fact, the latter three senses have to do with materiality and its immediately sensible qualities: smell, with the material volatilisation of air; taste, with the material dissolution of objects; touch, with the warm, the cold, the smooth. ${ }^{19}$ Even if this paradigm served a purpose in the process of constituting modern art and aesthetics, today it appears inadequate and impracticable..$^{20}$

The idea that the art of cooking would consist in the visual 'beauty' of a dish is a construction related to the ocularcentrism of modern aesthetics. Besides the by now obvious appreciation of the relevance played by vision vis-à-vis taste, we need to go a step further so as to generate a thinking and practice for the perceiving body in which taste and sight would be co-implicated as a corresponding relation. This, however, implies a need to think strategically about the possibility of an art of cooking that would not depend on being beautiful to the eye, but rather enjoyable to eat. Such gustatory good would be the artistic fact. Food is not consumed and does not disappear.

19 See Serres, Les Cinq sens.

${ }^{20}$ See Carolyn Korsmeyer, Making Sense of Taste: Food and Philosophy (Ithaca, NY: Cornell University Press, 1999) and Telfer, Food for Thought. 
Rather, it is transformed and transforms us. We must overcome the fixation on a visible and permanent object. In an aesthetic model that is not tied to formal representation, other aspects related to consumption, metabolism and transformation are to be valorised too. Food always leaves a trace in both mind and body. Accordingly, food images have a key role in expressing a fundamental duality that they can and must clarify. An image is profound if it succeeds in suggesting that cooking is not (merely) visual art, but rather art in respect to vision, technical skill, care, passion and work.

We must thus overcome the idea that the art of cooking would principally consist in the design and the ideational project, that precedes its preparation and actualisation, prefiguring them. Here too a visual prejudice is at play: ideas (from the Latin video, to see) are mental images, visions. The hand, however, is as creative as the head, as shown by palaeontology, anthropology and evolutionary psychology, as well as by the observation of all that happens in a kitchen. It is a matter of understanding the correlation between head and hand, body and mind. The word ductus indicates the gesture that links the executor, the creator, to the matter she is handling. However, when passion, awareness and care are present - as is the case in any great cooking - the ductus is not a merely passive reproduction: it is creative and always generative of something more than the idea. ${ }^{21}$ The continuous perfecting of high-level artisan

${ }^{21}$ See Richard Sennett, The Craftsman (New Haven, CT and London: Yale University Press, 2008); Tim Ingold, The Perception of the Environment: Essays on Livelihood, Dwelling and Skill (London and New York: Routledge, 2000); Tim Ingold, Making: Anthropology, 
work - as is the case of any activity in which the body has a central role, such as in sports - depends on an 'obsessive energy', that is, a drive that produces the artisanal selfimprovement. Accordingly, every gesture is not a mere (passive) repetition of the former, but rather a supplementary evolution, in the sense of an all-encompassing corporeal knowledge that constantly evolves, in and through the relation between the matter (in this case, food) and the hand. The apprenticeship and expertise of the cook may thus lead to an infinite self-perfecting. It is within such a capacity for repetition that the spaces of creative freedom may be found. This opens greater possibilities and allows the overcoming of the dichotomy - again, a modern one, unknown to both the premodern world - between artistcreator and artisan-executor. The great cooks are always creative, because they do not work mechanically on matter, but rather with matter. They test its breaking points, articulations and possibilities vis-à-vis the result they aim to obtain, and often the objective is modified during the practice. Cooking is therefore art, both in the sense of the project and the idea, and that of the ductus. Often the two aspects co-exist, and occasionally one might prevail: what counts, however, is the final result.

The earlier suggestion to conceive of the relation between sight and taste as a relational and non-hierarchical

Archaeology, Art and Architecture (London and New York: Routledge, 2013); Krina Patel, Thinkers in the Kitchen: Embodied Thinking and Learning in Practice (Cambridge: Harvard Graduate School of Education, 2008). For the concept of ductus see Jacques Derrida, The Truth in Painting (Chicago, IL: University of Chicago Press, 1987). 
correspondence, has numerous ethical implications (the image is always ethical, as Didi-Hubermann aptly noticed). ${ }^{22}$ I shall indicate here just one, which I think is of the greatest importance: the deconstruction and overcoming of the gender issue. As it is known, the world of art cooking (in the sense in which we are dealing here) is almost entirely male. The primacy of vision over the other senses, as well as of the design over the ductus, gives rise to the idea that the cook would become a culturally 'elevated' figure only when, more than cooking, he thinks cooking, and projects dishes. The French word chef expresses well this axiology: according to the historian Jean-François Revel, a chef is a man able to invent what has not yet been eaten at home. ${ }^{23}$ The chef is a chief, someone who commands and that today is often thought of as the intellectual: a head and a mouth, but not necessarily a hand. Or rather, the hand is not part of the conception of culinary art. It is not difficult to appreciate the implications of this approach with respect to the question of gender, and the prejudices and subordinations it implies. Instead, it is important to think of cooking as art only when the significance of the concerned relation with food becomes palpable: a relation that originates in the (often but not necessarily always) maternal gesture of nourishing and of caring for well-being. All cooks, of all genders, should be aware of this, independently of the style they decide to pursue. To be sure, today this awareness seems

22 See George Didi-Huberman, Images in Spite Of All: Four Photographs from Auschwitz (Chicago, IL: University of Chicago Press, 2008).

23 See Jean-François Revel, Culture and Cuisine: A Journey through the History of Food (Boston, MA: Da Capo Press, 1982). 
to be growing: haute cuisine seems increasingly to valorise intimate elements, those tied to domesticity, infancy and the transmission of savoirs and tastes (in Italian: saperi e sapori). As a form of compensation for a hierarchy everyone perceives to be limited and inadequate, what occurs instead is a sort of general maternalisation of the style of at least a part of contemporary cooking.

In this way, the taste of vision may also become the taste of memory. In this case, sight concedes us something that taste does not. As for the wine label, the visual image may help our comprehension and reflection, since cooking does not only inhabit the immediacy of the present. The gustatory experience is not just dissected and immediate; rather, every instant in which it takes place, reveals the infinite knots linking it to all the past instants, already consumed and only apparently lost. Sight might thus help us, in an apparently paradoxical way, to understand that (also) within taste and cooking there exist no progress. What exists instead is their continuous expansion, wherein new expressive possibilities are integrated, boundaries widened, novel paths drawn, within the awareness that it is always possible to turn or return from where we started. Because the time of taste is not a straight line but rather a circle or, better, a spiral.

\section{References}

Austin, John L. How to Do Things with Words. Oxford: Oxford University Press, 1962.

Borghini, Andrea. 'On Being the Same Wine.' Rivista di Estetica 51 (2012): 175-92. 
Bottinelli, Silvia and Margherita d'Ayala Valva, eds. The Taste of Art: Cooking, Food and Counterculture in Contemporary Practices. Fayetteville, AR: University of Arkansas Press, 2017.

Carême, Marie-Antoine. Le pâtissier pittoresque. Paris: Hachette, 2013.

Davidson, Sylvie and Fabrizio Lollini, eds. Le arti e il cibo: Modalità ed esempi di un rapporto. Bologna: Bononia University Press, 2014.

Derrida, Jacques. Writing and Difference. Chicago, IL: University of Chicago Press, 1978.

- The Truth in Painting. Chicago, IL: University of Chicago Press, 1987.

Dickie, George. The Century of Taste: The Philosophical Odyssey of Taste in the Eighteenth Century. Oxford and New York: Oxford University Press, 1996.

Didi-Huberman, George. Images in Spite of All: Four Photographs from Auschwitz. Chicago, IL: University of Chicago Press, 2008.

Gibson, James J. The Senses as Perceptual Systems. Boston, MA: Houghton Mifflin, 1966.

Ingold. Tim, The Perception of the Environment: Essays on Livelihood, Dwelling and Skill. London and New York: Routledge, 2000.

- Making: Anthropology, Archaeology, Art and Architecture. London and New York: Routledge, 2013.

- The Life of Lines. London and New York: Routledge, 2015.

Korsmeyer, Carolyn. Making Sense of Taste: Food and Philosophy. Ithaca, NY: Cornell University Press, 1999.

—. 'Aesthetic Deception: On Encounters with the Past.' Journal of Aesthetics and Art Criticism 66, no. 2 (spring 2008): 117-27.

_. 'Touch and the Experience of Genuine.' British Journal of Aesthetics 52:4 (October 2012): 365-77. 
Lipovetsky, Gilles, and Jean Serroy. Lesthétisation du monde:

Vivre à l'âge du capitalism artiste. Paris: Gallimard, 2013.

Marrone, Gianfranco. Gastromania. Milano: Bompiani, 2014a. . 'Goodman in cucina: le attivazioni di Babette.' In Cibo, filosofia e arte, edited by Nicola Perullo, 69-81. Pisa: ETS, 2014.

Merleau-Ponty, Maurice. The Visible and the Invisible. Evanston, IL: Northwestern University Press, 1969.

- Phenomenology of Perception. New York: Routledge, 2012.

Patel, Krina. Thinkers in the Kitchen: Embodied Thinking and Learning in Practice. Cambridge: Harvard Graduate School of Education, 2008.

Perullo, Nicola. 'Can Cuisine be Art? A Philosopical (and Heterodox) Proposal.' In The Taste of Art: Cooking, Food and Counterculture in Contemporary Practices, edited by Silvia Bottinelli and Margherita d'Ayala Valva, 23-44. Fayetteville, AR: University of Arkansas Press, 2017.

— ed. 'Wineworld. Wine, Taste, Philosophy and Aesthetics.' Rivista di Estetica 51 (2013): 3-48.

- Taste as Experience: The Philosophy and Aesthetics of Food. New York: Columbia University Press, 2016.

Revel, Jean-François. Culture and Cuisine: A Journey through the History of Food. Boston: Da Capo Press, 1982.

Sennett, Richard. The Craftsman. New Haven, CT and London: Yale University Press, 2008.

Serres, Michel. Les cinq sens. Paris: Grasset, 1985.

Shapin, Steven. 'The Sciences of Subjectivity'. Social Studies of Science 43 (2012): 170-184.

Telfer, Elizabeth. Food for Thought: Philosophy and Food. New York: Routledge, 1996. 
